\title{
Seeming Ambivalent, Being Prejudiced: The Moderating Role of Attitude Basis on Experienced Affect
}

\author{
Sandro Costarelli \\ University of Trento, Italy
}

\begin{abstract}
One experiment examined the potential for ambivalence toward the outgroup based on cognitive but not affective information to be functional to justify the prior expression of prejudice. To this end, the (prejudice expression vs. no prejudice expression) context of holding ambivalence toward the outgroup was manipulated before assessing all participants' cognitively based ambivalence and affectively based ambivalence toward the outgroup. Finally, all participants self-reported their positive affect. As predicted, participants whose prejudice was previously assessed, exhibited increased levels of positive affect to the extent that they were cognitively but not affectively ambivalent toward the outgroup. By contrast, replicating prior work, participants whose prejudice was not previously assessed exhibited decreased levels of positive affect to the extent that they were both cognitively and affectively ambivalent toward the outgroup. Consistent with recent, functional approaches to the conceptualization of attitude structure and prejudice, these findings provide direct evidence that cognitively based ambivalence toward the outgroup can contribute to the need to be prejudicial. The implications of these findings for ambivalence and intergroup research are discussed.
\end{abstract}

Keywords: ambivalence, intergroup emotions, prejudice, affect, attitude structure

Imagine the following scenario. John has come back home from a year off which he spent in Mexico. One day he bumps into a friend. When asked about the locals in that foreign country, John replies, “I still don't know... Mexicans are very helpful, and so on... At the same time, I also have to say that they are so unorganized. .."

The above scenario demonstrates an example of outgroup ambivalence. Such an attitude occurs when the members of a group other than one's own are the target of a simultaneously positive and negative evaluation (Scott, 1966, 1969; for reviews, see Jonas, Broemer, \& Diehl, 2000; Thompson, Zanna, \& Griffin, 1995). This peculiar type of intergroup attitude is prominent in intergroup contexts (Katz, Wackenhut, \& Hass, 1986), as demonstrated by research conducted on a large number of groups. These

This article was published Online First November 8, 2010. Sandro Costarelli, DiSCoF Department, University of Trento, Italy.

Correspondence concerning this article should be addressed to Sandro Costarelli, DiSCoF Department, Corso Bettini, 31, 38068 Rovereto (Tn), Italy. E-mail: sandro .costarelli@unitn.it include African Americans (e.g., Gaertner \& Dovidio, 1986; Katz et al., 1986; McConahay, 1983), homosexuals (e.g., Haddock, Zanna, \& Esses, 1993), immigrants (e.g., Bell \& Esses, 1996; Maio, Bell, \& Esses, 1996), and women (e.g., Glick, Diebold, Bailey-Werner, \& Zhu, 1997; Glick \& Fiske, 1996; MacDonald \& Zanna, 1998).

Although outgroup ambivalence has received a great deal of theoretical and empirical attention, there has been little emphasis on the selfprotective properties of this peculiar type of intergroup attitude. Accordingly, the current paper focuses on the notion that people may express ambivalence toward (the members of) a group as a way of "getting away" with the expression of prejudice toward that group. Traditionally, because of the prevailing theoretical popularity of cognitive consistency theories (e.g., Brehm \& Cohen, 1962; Heider, 1958), attitudes toward outgroups have been conceptualized as being one-sided, and specifically relatively negative (compared to ingroup attitudes). This phenomenon (prejudice) has been one of the core issues ever since the beginning of research and theorizing in social psychology. At first blush, outgroup attitudes that are structur- 
ally one-dimensional (e.g., prejudice) and bidimensional (e.g., ambivalence) appear to be inherently incompatible to hold by the same individual. However, the attitudinal condition of being ambivalent and its relation with holding prejudiced attitudes is a major focus of prejudice research (e.g., Gaertner \& Dovidio, 1986; Glick \& Fiske, 1996; Haddock et al., 1993; Katz et al., 1986; Monteith, 1996). Among others, one of the core issues of this empirical work has been the affective response to one's own ambivalence toward otherwise prejudiced groups. In line with the theory of Racial ambivalence (Katz \& Hass, 1988), this prior work has found outgroup ambivalence to be negatively related to subsequent positive affect (e.g., Britt, Boniecki, Vescio, Biernat, \& Brown, 1996; Hass, Katz, Rizzo, Bailey, \& Moore, 1992; Monteith, 1996).

However, more recent work suggests that negative affective responses to one's own outgroup ambivalence are not as ubiquitous and immutable as they were considered until 10 years ago. For instance, Maio and his colleagues (Maio, Greenland, Bernard, \& Esses, 2001) have argued that outgroup ambivalence can increase subsequent positive affect. Specifically, this may be the case when people perceive that expressing both positive and negative elements at the same time regarding the outgroup can make appear ambivalence as a balanced and realistic appraisal of outgroup members. Some research at the interpersonal level is also in line with this reasoning. For example, Cavazza and Butera (2008) have demonstrated that people perceive expressing ambivalence as a contribution to their defense of one side or the other of a discussion issue, depending on what the specific situation requires. According to these researchers, ambivalence can serve the function of contributing to people's fitting and coping with diverse situational demands. Thompson and Holmes (1996) have also provided the same account for their finding that people experience positive affect to the extent that they are ambivalent toward their romantic partner. In sum, there is emerging evidence that the affective responses to one's outgroup ambivalence are malleable and may undergo some changes in their valence. With respect to prejudice, the challenge is thus to identify the specific factors that might moderate the positive versus negative consequences for the affective response of the individual expressing his or her ambivalence toward the members of a prejudiced group.

To this end, the current study adopts an approach that is different from previous work in this area. Specifically, one instance of the notion that affective responses are context-dependent (Martin \& Whitaker, 2000) is that people may experience emotions both as an individual and as a group member (Smith, 1993). This suggests that, rather than being only a response to individually held standards for intergroup evaluation (the personal level) as argued in previous individual-based research on the affective consequences of one's own outgroup ambivalence (e.g., Britt et al., 1996; Hass et al., 1992; Monteith, 1996), such affective consequences may also be a response to identity-relevant issues related to the intergroup context (the social level).

Under this specific theoretical assumption, the present paper considers outgroup ambivalence-affect relationships within the more general functional approach to the study of attitudes (e.g., the Function-Structure model [FSM]; Maio \& Olson, 2000) by investigating the functional potential for outgroup ambivalence that is predicted by a recently proposed model of prejudice (the Justification-Suppression model [JSM]; Crandall \& Eshleman, 2003; also see Crandall, Eshleman, \& O'Brien, 2002). In the JSM, outgroup ambivalence is viewed as being conducive to group members' positive affect by contributing to the unsanctioned expression of their prejudice. To date, however, no empirical work has tested this prediction. Thus, unlike previous research, the present study tests whether outgroup ambivalence is a positive predictor of subsequent positive affect after expressing prejudice, while also trying to replicate the findings of prior research in a no prejudiceexpression condition, where a negative relation should be found. Thus, finding support for predictions formulated for both experimental conditions would contribute to reconcile the mixed findings of previous work on outgroup ambivalence-affect relationships.

\section{Prejudice Expression, Basis of Outgroup Ambivalence, and Subsequent Affect}

According to the JSM, expressing ambivalence toward outgroups elicits group members' 
positive affect because it allows them to express prejudice instead of suppressing it. On the one hand, some psychological factors create prejudice within people, a negative evaluative tendency that has motivational force with respect to its public expression. On the other, social norms and personal standards run against this need to express one's prejudice by motivating people to suppress the expression of prejudice as well as its private acceptance.

However, while being generally successful, this process entails some affective costs. First, since prejudice expression is primary, its suppression is countermotivational. Furthermore, prejudice suppression takes some mental energy to be enacted, whereby creating a state of tension in the individual. As a consequence, according to the JSM, people are motivated to use a number of psychological strategies that allow the unsanctioned expression of their prejudice, thereby avoiding its suppression and the concurrent tension it entails. In particular, one of such strategies is precisely to express one's ambivalent attitude toward the outgroup that is the target of one's prejudicial attitudes. Importantly, prior work has shown the positive affective consequences of releasing tension because of previous prejudice suppression by means of its public expression (e.g., O'Brien \& Crandall, 2003). Accordingly, the JSM predicts that outgroup ambivalence is conducive to a state of release from the aversive emotional by-product of prejudice suppression by serving as a justification of ones' prejudice expression.

In this respect, an important specification made by the JSM is that the cognitive versus affective basis of the specific information forming ambivalent attitudes toward the outgroup moderates the potential for outgroup ambivalence to justify prejudice expression. This notion is consistent with past attitude research showing that some types of psychological responses depend on whether evaluative associations with valenced information are primarily activated by feelings and emotions or by beliefs about the attitude object's properties (e.g., Breckler, 1994; Breckler \& Wiggins, 1989; Crites, Fabrigar, \& Petty, 1994; Millar \& Tesser, 1996; Trafimow \& Sheeran, 1998; Zanna \& Rempel, 1988; see Eagly \& Chaiken, 1993; Haddock \& Zanna, 1999, for reviews).

Accordingly, in the JSM, ambivalence in one's outgroup-based affect is defined as a con- flict between the default negative emotions elicited by outgroup members (i.e., prejudice) and positive emotions that serve as its suppressors. In other words, since the model defines prejudice as unambivalently negative feelings toward outgroup members, affect-based outgroup ambivalence is by definition bound to suppressed prejudicial attitudes and the resulting tension.

Therefore, more important for the scopes of the current study, in the JSM the public expression of affect-based outgroup ambivalence is viewed as lacking the potential to justify prejudice, and elicit positive affect as a consequence. Indeed, this notion is consistent with the evidence provided by the extant research on the outgroup ambivalence-affect association reviewed above (e.g., Britt et al., 1996; Hass et al., 1992; Monteith, 1996). Unsurprisingly, since this prior work operationalized outgroup ambivalence as only being affect-based, it also found evidence of a robust positive association with subsequent negative affect.

However, ambivalence may also be a conflict between positive and negative beliefs about the attributes of outgroup members (or stereotypes; Ashmore \& Del Boca, 1981). In this respect, cognition-based outgroup ambivalence can be defined as an ambivalent outgroup stereotype. Of relevance for the scopes of the current study, the JSM predicts that stereotypes are one of the cognitive devices that can serve the psychological function of justifying the expression of prejudice. Thus, consistent with this specification of the JSM, the experience of subsequent positive affect should follow to the extent that outgroup stereotypes are ambivalent in content as expressed by cognition-based outgroup ambivalence.

Importantly, this prediction is also consistent with the Function-Structure model of attitudes (Maio \& Olson, 2000), which proposes that the differential predictive power of cognition-based versus affect-based attitude components reflects the extent to which each component contains information that is relevant to the situational goals. Based on this argument, Maio and colleagues (2001) suggest that cognitively based ambivalence toward outgroup members can be a positive predictor of positive affect. This should occur because holding an attitude toward the members of a group that is simultaneously positive and negative may be regarded as a defensible, balanced, and realistic reaction to 
one's appraisal of both the positive and the negative stereotypic traits of the relevant outgroup's members.

\section{Hypotheses}

On the basis of this prior theoretical and empirical work, under conditions of prejudice expression, cognitively but not affectively based outgroup ambivalence should contribute to the motivated desire to express one's otherwise suppressed prejudice. Accordingly, cognitively based outgroup ambivalence and subsequent positive affect should be positively related. In contrast, consistent with prior research (e.g., Britt et al., 1996; Hass et al., 1992; Monteith, 1996) and theorizing (Katz \& Hass, 1988), affectively based outgroup ambivalence should not be a predictor of positive affect. Consistent with the JSM, this pattern of results should emerge even when potential, individual differences in ingroup identification are controlled for by partialing out its potential influence.

In contrast, consistent with prior research (e.g., Britt et al., 1996; Hass et al., 1992; Monteith, 1996) and theorizing (Katz \& Hass, 1988), under conditions of no prejudice expression, both cognitively and affectively based outgroup ambivalence should be negatively related to subsequent positive affect. Again, this pattern of results should emerge even when potential, individual differences in ingroup identification are controlled for by partialing out its potential influence.

\section{Method}

\section{Participants and Design}

Two hundred psychology students from the University of Trento, Italy (113 women and 87 men; age: $M=19.37, S D=1.55)$ took part in the experiment. Participants were randomly assigned to one of two experimental conditions manipulating the (prejudice expression vs. no prejudice expression) context of expressing ambivalence toward the outgroup. No gender effects or interactions were expected, nor were any observed, $F$ s $<2.45, n s$. Thus, gender was omitted from later analyses.

\section{Procedure}

At the start of a regular lecture, an experimenter invited students to participate in the study. Participants were provided with a questionnaire, which was announced as part of a data collection of a "Europe Survey." As a cover story, participants were told that the current questionnaire would be focused on their attitudes toward immigrants in their native country. At the onset, participants expressed their ingroup identification with the ingroup (Italians). Then, on negative items, half of the participants were given an opportunity to express their prejudice toward the outgroup (immigrants in Italy as a general category, a particularly salient social group because of the harsh political debate that a newly implemented immigration law has generated in the country). The rest of the participants were not given such an opportunity. Rather, on the very same items, they expressed their attitude toward their parents (a social group toward which it is reasonable to expect some ambivalence but no prejudice). Subsequently, all participants expressed both cognitively based and affectively based ambivalence toward immigrants in Italy. Finally, participants self-reported their positive affect and provided demographic data. After the data were collected, participants were debriefed.

\section{Measures}

Unless otherwise mentioned, all ratings described in this paper were made on 6-point Likert-type scales ranging from 1 (= not at all) to 6 (= very much).

Ingroup identification. Ingroup identification was assessed by Doosje, Ellemers, and Spears' (1995) ingroup identification measure. A Principal components analysis was used to determine the dimensions underlying the items comprising the scale. A one-factor solution was obtained which accounted for $74 \%$ of the variance in participants' responses (factor loadings $>|.81|$ ). Consistent with that, a composite scale score was created by averaging ratings across items. The scale was internally consistent (Cronbach's $\alpha=.88$ ).

Prejudice. Prior theoretical and empirical work suggests that the cognitive and affective dimensions of prejudice are somewhat distinct components of prejudiced attitudes (e.g., Esses, Haddock, \& Zanna, 1993; Mann, 1959; Pettigrew, 1997; Stangor, Sullivan, \& Ford, 1991). Cognitive prejudice is based on one's beliefs 
about the members of a group (Ashmore \& Del Boca, 1981; Katz \& Hass, 1988; Ostrom, Skowronski, \& Novak, 1994). In contrast, affective prejudice is based on one's feelings and emotional responses to the members of a group (Esses et al., 1993; Smith, 1993; Stangor et al., 1991). Accordingly, participants were asked to express prejudice on cognitive and affective dimensions. Cognitive prejudice was expressed by 4 negative trait items (foolish, dumb, violent, ignorant) as being relatively more associated with members of the ingroup or those of the outgroup. Affective prejudice was expressed by 4 negative emotion items (hatred, disdain, disliking, disapproval) derived from Stephan and Stephan's (1993) theory of Affect-based prejudice that had been, or were anticipated to be, felt relatively more often during contact with members of the ingroup or those of the outgroup. Each of the items was administered to participants on a 7-point bipolar scale that allowed the direct expression of prejudice, ranging from -3 (= It applies much more to Italians than immigrants to $+3=$ It applies much more to immigrants than Italians). In the control group, participants rated the outgroup (their parents) on the same items, but the evaluation was not an intergroup one. As a consequence, the lack of any reference to the ingroup did not allow the participants in the control group to express prejudice.

Outgroup ambivalence. Ambivalent attitudes toward the outgroup was operationalized as responses to each of a list of 16 adjective items purportedly concerning members of the target groups (Kaplan, 1972). The items were in fact components of 8 pairs of antonyms. Eight unipolar items were in fact components of four cognitively based pairs of antonyms (i.e., intelligent-unintelligent, competent-incompetent, precise-superficial, hardworking-lazy) aimed at assessing cognitively based positive and negative attitudes toward the outgroup. The other eight unipolar items were components of four affectively based pairs of antonyms (i.e., I feel intrigued by them-I do not feel intrigued by them, I feel admiration for them-I disapprove them, nicenasty; I feel amused by them-I feel bored by them) aimed at assessing affectively based positive and negative attitudes toward the outgroup. All antonyms were evaluative in nature. However, consistent with the suggestion of Crites, Fabrigar, and Petty (1994; also see Breckler \& Wiggins, 1989), the cognitively based antonyms were focused on the instrumental characteristics of outgroup members, whereas the affectively based antonyms were focused on the emotions evoked in respondents by outgroup members. Participants were asked to indicate the degree to which each item fitted their thoughts about, or feelings evoked by, the members of the outgroup as a group and not as single individuals. The items were administered to participants while being counterbalanced for rating order. No rating order effects or interactions were expected, nor were any observed, $F \mathrm{~s}<3.12, n s$. Therefore, rating order was omitted from later analyses. The moderate intercorrelations among the four resulting attitude rating scales $(|.43|<r<|.61|)$ suggest that these latter reflect conceptually related but distinct (nonredundant) constructs. Ratings of the outgroup expressed both on the positively and the negatively valenced cognitive items and on the positively and the negatively valenced affective items were moderately correlated ( $r \mathrm{~s}=-0.43$ and -0.50 , respectively). Therefore, the computation of outgroup ambivalence appeared methodologically justified. Accordingly, outgroup ambivalence scores were computed for each participant. Among the various existing indices (see Breckler, 1994; Priester \& Petty, 1996, 2001; see Thompson et al., 1995, for a comparative review), the Griffin's formulation was used to calculate ambivalence (as per Thompson et al., 1995). This formula produces a score that is a function of the simultaneous intensity of the positive and negative ratings, $(\mathrm{P}+\mathrm{N}) / 2-$ $|\mathrm{P}-\mathrm{N}|$, where $\mathrm{P}=$ positive attitude score, and $\mathrm{N}=$ negative attitude score. These calculations were performed for each attitude domain (i.e., cognition-based and affect-based). The moderate correlation between cognitively based outgroup ambivalence and affectively based outgroup ambivalence $(r=.56)$ indicates that the two measures, while being related, possess discriminant validity.

Positive affect. Self-reported positive affect was assessed with an affect adjective list. This list was modeled after the circumplex model of affective experiences developed by Watson and Tellegen (1985). The selection of the adjectives was guided by the goal to repre- 
sent one of the two octants of the model representing positive affect. Prior work on the structure of affective experiences suggests that there are at least two highly distinct dimensions of positive affectivity (e.g., Friedrickson, 1998; Watson \& Tellegen, 1985; Watson, Wiesie, Vaidya, \& Tellegen, 1999). One is environment-centered and the result of goal pursuit; the other is self-centered and the result of goal achievement. In the current study, this latter rather than the former dimension of participants' positive affective response was assessed by including those affect adjectives that have been used in past research to measure this specific dimension of positive affectivity (e.g., Kunzman \& Baltes, 2003). This choice was driven by the fact that this latter taps on the hypothesized potential for (cognitively based) outgroup ambivalence to evoke positive affect under conditions of prejudice expression because of its achieving the psychological goal of "covering" prejudice expression (as detailed above). For this reason, participants' negative affective response was not expected to have any predictive value and was therefore not assessed.

Participants were asked to indicate the extent to which each of five positive emotion adjectives (happy, proud, calm, cheerful, satisfied) applied to how they were feeling. Participants were instructed not to think too much about their ratings and instead to give quick, gut-level responses. This precise indication was meant as providing participants with the sense that they should not experience any guilt with respect to their prior evaluation of the outgroup. Finally, a positive affect index was constructed by averaging each participant's score for the items. This choice was validated by the results of a Principal components analysis on the emotion items. A one-factor solution was extracted accounting for $79 \%$ of the variance. All factor loadings exceeded .79. Furthermore, this combined measure had a very good internal consistency $(\alpha=.86)$.

\section{Results}

There were no significant differences between the design cells in ingroup identification and overall attitude toward the outgroup, $t \mathrm{~s}<$ $|1|$, ns. This indicated that randomization of participants was successful.

\section{Main Analyses}

First, in a hierarchical multiple regression analysis, using product terms representing the interactions (Aiken \& West, 1991; Baron \& Kenny, 1986), a dummy — coded variable representing the prejudice expression manipulation (no prejudice-expression condition $=0$; prejudice-expression condition $=1$ ) and the composite score for cognitively based outgroup ambivalence and affectively based outgroup ambivalence, were entered as predictor variables. Positive affect was the criterion variable. Participants' average ingroup identification score was also entered in the model, to control for individual differences in this variable. Following Aiken and West's suggestion (1991), first, scores for cognitively based outgroup ambivalence, affectively based outgroup ambivalence, and ingroup identification were centered around the mean. Then these scores were entered into Step 1 of the model, $F(1,199)=2.31, p<.05$, all possible two-way interactions were inserted into Step 2, F change $=3.57, p<.05$, and the three-way interaction of the variables was also inserted into Step 3 of the model, $F$ change $=0.57, n s$. The final regression model accounted for $31 \%$ of the variance. Ingroup identification was a significant predictor, $B=.51, S E=.12$, $t=2.50, p<.05$. As expected, affective ambivalence was a negative predictor of positive affect, $B=-0.31, S E=.14, t=-2.11, p<$ .05 , but did not interact with the prejudice expression manipulation, $t=0.41, n s$. In contrast, the critical interaction of the prejudice expression manipulation and cognitive ambivalence was significant, $t=6.47, p<.05$. No other main effects or interactions were statistically significant, $t \mathrm{~s}<|1.31|, p \mathrm{~s}>.20$.

Simple tests of the relationship between cognitively based ambivalence and positive affect were conducted within each experimental condition. As predicted, the relationship between cognitive ambivalence and positive affect was significantly negative in the no-prejudice expression condition $B=-0.59, S E=.17, t=$ $-3.34, p<.005$, but significantly positive in the prejudice expression condition, $B=.41$, $S E=.15, t=2.67, p<.01$. The two correlations differed significantly from each other, $z=$ $-7.75, p<.05$. Thus, as expected, cognitively based outgroup ambivalence predicts positively or negatively subsequent positive affect de- 
pending on whether it is held after expressing or after not expressing prejudice, respectively.

\section{Discussion}

The results from the current study clearly support a functional role of outgroup ambivalence in the motivated expression of prejudice, a process at the core of a recently proposed model (JSM; Crandall \& Eshleman, 2003). Indeed, first, participants who had been given the opportunity to express previous prejudice experienced more positive affect to the extent that they were ambivalent toward immigrants. This effect was reversed for participants who had not been given the opportunity to express previous prejudice, who experienced less positive affect to the extent that they were ambivalent toward immigrants. Importantly, this pattern of findings remained unchanged after individual differences in ingroup identification were controlled for. These results suggest that ambivalence toward outgroup members buffers subsequent positive affect only when it is reported after previous prejudice expression. When this is not the case, outgroup ambivalence decreases the level of subsequent positive affect, a robust finding of past ambivalence research (e.g., Britt et al., 1996; Hass et al., 1992; Monteith, 1996).

Consistent with the emerging functional approach to the understanding of attitude structure in general (e.g., FSM; Maio \& Olson, 2000) and recent functional construals of outgroup ambivalence in particular (e.g., Maio et al., 2001), at issue in the present study was whether the ambivalence-affect association at stake can be moderated by some yet unidentified factors. Specifically, the current idea was that such moderator(s) should be necessarily related with the functional potential of outgroup ambivalence for contributing to the motivated need of expressing prejudice rather than suppressing it (JSM; Crandall \& Eshleman, 2003).

In this respect, a further finding of the present study supports this functional construal of outgroup ambivalence under conditions of prejudice expression. Specifically, results indicated that the cognitive versus affective basis of ambivalent attitudes toward the outgroup moderated whether such attitudes were positively or negatively related to subsequent positive affect, respectively. Indeed, for participants who had been previously given the opportunity to ex- press their prejudice, the more ambivalent they were in their beliefs about immigrants, the more positive their subsequent mood. By contrast, to the extent that participants who had been previously given the opportunity to express their prejudice were ambivalent in their emotions regarding immigrants, their subsequent mood was less positive. This latter finding is in line not only with the affectively unpleasant character of emotional ambivalence toward the outgroup predicted by the JSM (Crandall \& Eshleman, 2003) but also with the unpleasant effects of the predominantly affective operationalization of outgroup ambivalence found in previous research (e.g., Britt et al., 1996; Hass et al., 1992; Monteith, 1996). Conceptually, this result from the present study suggests that affectbased ambivalence toward the outgroup does not have the functional potential to contribute to the motivated need of expressing prejudice as cognition-based outgroup ambivalence does.

This suggests that the relatively more ambivalent people in their beliefs about the outgroup seem to benefit from the fact that they perceive such cognitive ambivalence as an attitude that others will view as being "balanced" by the fact that it is positively and negatively valenced at the same time (Maio et al., 2001). This suggests that people perceive ambivalence in cognitionbased attitudes toward outgroup members (i.e., outgroup stereotypes) as providing them with sufficient "rational" justification to feeling for outgroup members less positively, relative to ingroup members (i.e., outgroup prejudice). As a consequence, as demonstrated in the current study, the greater subsequent levels of positive affect that people experience to the extent that they have expressed cognitive outgroup ambivalence reflects their satisfaction with achieving the goal of "getting away" with the expression of a socially and personally sanctioned form of attitude toward outgroup members (i.e., being prejudiced) in a covert way (i.e., seeming ambivalent).

This finding is suggestive of a somewhat paradoxical process that may be currently present in the context of countering the negative societal consequences of expressing prejudice rather than suppressing it. Specifically, the current results demonstrate that while being normatively appropriate, suppressing the expression of one's prejudice is an affectively punished tension-building pro- 
cess (see the results of the no-prejudice condition). However, the present results also show that in presence of a viable psychological device (e.g., ambivalence), the otherwise counternormative expression of prejudice can be released, this being perceived as an affectively rewarded tension-release process. Conceivably, this may well be a path for even the reinforcement of (the otherwise counternormative) prejudice expression through operant conditioning to take place. Clearly, the implication of this ironic process is that suppressing one's own prejudice can paradoxically increase its expression, a "rebound effect" in a domain outside of the traditional one (i.e., stereotypes) that, to our knowledge, is undocumented as yet.

More generally, the results from the present study add significantly to the extant literature in several ways. First, they are novel in their contribution to reconcile the inconsistency of previous empirical (e.g., Britt et al., 1996; Hass et al., 1992; Monteith, 1996) and theoretical work (e.g., Maio et al., 2001). Importantly, the current findings have the added strength that they were obtained in a single study where the measures and research procedure were consistent across all participants. Besides, the present study provides the first direct test of the predictions of the JSM regarding the positive relationship between cognition-based outgroup ambivalence (equilibrium ambivalence, in the model's terminology) on the one hand, and subsequent pleasant affect on the other. Finally, not only does the current study provide novel evidence in support of such predictions but also supports the FSM with reference to social attitude objects.

\section{Limitations and Directions for Future Research}

The present work does have at least a limitation. Specifically, although ingroup identification was measured at the onset of the study to increase salience of participants' group membership, a measure of participants' level of selfcategorization at the social (group) level (Turner, Hogg, Oakes, Reicher, \& Wetherell, 1987) was absent. Although the observed effects are not easy to explain without this assumption, future research in this area could profit from the inclusion in the research design of a manipulation of self-categorization (at the individual vs. social level, and for which one could predict to replicate the current pattern of findings only for participants in the latter but not the former design cell).

\section{Conclusion}

The results from the present study point to the importance of truly integrating a multidimensional view of ambivalent attitudes into theory and research. Cognitive and affective dimensions of attitudes are relevant not only for univalent but also for ambivalent attitudes (Thompson et al., 1995), and this should be reflected in how ambivalence is conceptualized and measured. On a methodological level, ambivalence measures not including both cognitively and affectively based items do not allow the assessment of the potential (unique or interactive) roles played by the affective versus cognitive informational basis of ambivalent attitudes in predicting subsequent affective states. Thus, it is important to include paradigms, such as the current one, which permit the assessment of both cognitively and affectively based ambivalence.

On a conceptual level, future empirical work should further incorporate the idea that the influence simultaneously positive and negative evaluations may exert on subsequent affective states may depend on the context in which such attitudes are held (Jonas et al., 2000; see also Martin \& Whitaker, 2000). In line with recent functional models of attitude structure (e.g., Maio \& Olson, 2000), as the results from the present study indicate, considering ambivalence with respect to the motivated needs of the individual that holds such an attitude in a given psychological context (e.g., allowing vs. not allowing for prejudice expression) can provide a fruitful conceptual tool to predict the boundary conditions of ambivalence-affect associations. Finally, with regard to prejudice research, investigations of the positive affective consequences of outgroup ambivalence such as the present one can contribute to a further understanding of the ever changing subtle ways for intergroup prejudice to still make its way in the contemporary world. 


\section{References}

Aiken, L. S., \& West, S. G. (1991). Multiple regression: Testing and interpreting interactions. Newbury park, CA: Sage.

Ashmore, R. D., \& Del Boca, F. K. (1981). Conceptual approaches to stereotypes and stereotyping. In D. L. Hamilton (Ed.), Cognitive processes in stereotyping and intergroup behavior. Hillsdale, $\mathrm{NJ}$ : Erlbaum.

Baron, R. M., \& Kenny, D. A. (1986). The moderator-mediator variable distinction in social psychological research: Conceptual, strategic, and statistical considerations. Journal of Personality and Social Psychology, 51, 1173-1182.

Bell, D. W., \& Esses, V. M. (1996). Ambivalence and response amplification toward native peoples. Journal of Applied Social Psychology, 27, 10631084.

Breckler, S. J. (1994). A comparison of numerical indexes for measuring attitudinal ambivalence. $E d$ ucational and Psychological Measurement, 54, 350-365.

Breckler, S. J., \& Wiggins, E. C. (1989). Affect versus evaluation in the structure of attitudes. Journal of Experimental Social Psychology, 25, 253-271.

Brehm, J. W., \& Cohen, A. R. (1962). Explorations in cognitive dissonance. New York: Wiley.

Britt, T. W., Boniecki, K. A., Vescio, T. K., Biernat, M., \& Brown, L. M. (1996). Intergroup anxiety: A person X situation approach. Personality and Social Psychology Bulletin, 22, 1177-1188.

Cavazza, N., \& Butera, F. (2008). Bending without breaking: Examining the role of attitudinal ambivalence in resisting persuasive communication. European Journal of Social Psychology, 38, 1-15.

Crandall, C. S., \& Eshleman, A. (2003). A Justification-Suppression model in the expression and experience of prejudice. Psychological Bulletin, 129, 414-446.

Crandall, C. S., Eshleman, A., \& O'Brien, L. (2002). Social norms and the expression and suppression of prejudice: The struggle for internalization. Journal of Personality and Social Psychology, 82, 359-378.

Crites, S. L., Fabrigar, L. R., \& Petty, R. E. (1994). Measuring the affective and cognitive properties of attitudes: Conceptual and methodological issues. Personality and Social Psychology Bulletin, 20, 619-634.

Doosje, B., Ellemers, N., \& Spears, R. (1995). Perceived intragroup variability as a function of group status and identification. Journal of Experimental Social Psychology, 31, 410-436.

Eagly, A. H., \& Chaiken, S. (1993). The psychology of attitudes. Fort Worth, TX: Harcourt.
Esses, V. M., Haddock, G., \& Zanna, M. P. (1993). Values, stereotypes, and emotions as determinants of intergroup attitudes. In D. M. Mackie \& D. L. Hamilton (Eds.), Affect, cognition, and stereotyping: Interactive processes in group perception ( $\mathrm{pp}$. 137-166). San Diego, CA: Academic Press.

Friedrickson, B. L. (1998). What good are positive emotions? Review of General Psychology, 2, 300319.

Gaertner, S. L., \& Dovidio, J. F. (1986). The aversive form of racism. In J. F. Dovidio \& S. L. Gaertner (Eds.), Prejudice, discrimination, and racism (pp. 61-89). New York: Academic Press.

Glick, P., Diebold, J., Bailey, B., \& Zhu. L. (1997). The two faces of Adam: Ambivalent sexism and polarized attitudes among women. Personality and Social Psychology Bulletin, 23, 1324-1334.

Glick, P., \& Fiske, S. T. (1996). The Ambivalent Sexism inventory: Differentiating hostile and benevolent sexism. Journal of Personality and Social Psychology, 70, 491-512.

Haddock, G., \& Zanna, M. P. (1999). Cognition, affect, and the prediction of social attitudes. In W. Stroebe \& M. Hewstone (Eds.), European Review of Social Psychology, 10, 75-99.

Haddock, G., Zanna, M. P., \& Esses, V. M. (1993). Assessing the structure of prejudicial attitudes. The case of attitudes toward homosexuals. Journal of Personality and Social Psychology, 65, 11051118.

Hass, R. G., Katz, I., Rizzo, N., Bailey, J., \& Moore, L. (1992). When racial ambivalence evokes negative affect, using a disguised measure of mood. Personality and Social Psychology Bulletin, 18, 786-797.

Heider, F. (1958). Attitudes and cognitive organization. Journal of Psychology, 21, 107-112.

Jonas, K., Broemer, P., \& Diehl, M. (2000). Attitudinal ambivalence. In W. Stroebe \& M. Hewstone (Eds.), European Review of Social Psychology, 11, 35-74.

Kaplan, K. J. (1972). On the ambivalence-indifference problem in attitude theory and measurement: A suggested modification of the semantic differential technique. Psychological Bulletin, 77, 361372.

Katz, I., \& Hass, R. G. (1988). Racial ambivalence and value conflict: Correlational and priming studies of dual cognitive structures. Journal of Personality and Social Psychology, 55, 893-905.

Katz, I., Wackenhut, J., \& Hass, R. G. (1986). Racial ambivalence, value duality, and behavior. In F. Dovidio \& E. L. Gaertner (Eds.), Prejudice, discrimination, and racism (pp. 35-39). New York: Academic Press.

Kunzman, U., \& Baltes, P. B. (2003). Wisdomrelated knowledge: Affective, motivational, and 
interpersonal correlates. Personality and Social Psychology Bulletin, 29, 1104-1119.

MacDonald, T. K., \& Zanna, M. P. (1998). Crossdimension ambivalence toward social groups: Can ambivalence affect intentions to hire feminists? Personality and Social Psychology Bulletin, 24, 4, 427-441.

Maio, G. R., Bell, D. W., \& Esses, V. M. (1996). Ambivalence and persuasion: The processing of messages about immigrant groups. Journal of Experimental Social Psychology, 32, 513-536.

Maio, G. R., Greenland, K., Bernhard, M., \& Esses, V. M. (2001). Effects of intergroup ambivalence on information processing: The role of physiological arousal. Group Processes and Intergroup Relations, 4, 355-372.

Maio, G. R., \& Olson, J. M. (2000). Emergent themes and potential approaches to attitude function: The function-structure model of attitudes. In G. R. Maio \& J. M. Olson (Eds.), Why we evaluate: Functions of attitudes (pp. 417-442). Mahwah, NJ: Erlbaum, Inc.

Mann, J. H. (1959). The relationship between cognitive, affective, and behavioural aspects of racial prejudice. Journal of Social Psychology, 49, 223228.

Martin, L. L., \& Whitaker, D. (2000). Availability as input: The experience of cognitive effort can either strengthen or weaken evaluations. In H. Bless \& J. Forgas (Eds.), The message within: The role of subjective experience in social cognition and behavior (pp. 88-109). Philadelphia, PA: Psychology Press.

McConahay, J. B. (1983). Modern racism and modern discrimination: The effects of race, racial attitudes, and contexton simulated hiring decisions. Personality and Social Psychology Bulletin, 9, 551-558.

McGregor, I., \& Little, B. R. (1998). Personal projects, happiness, and meaning. On doing well and being yourself. Journal of Personality and Social Psychology, 74, 494-512.

Millar, M. G., \& Tesser, A. (1986). Effects of affective and cognitive focus on the attitude-behavior relation. Journal of Personality and Social Psychology, 51, 270-276.

Monteith, M. J. (1996). Contemporary forms of prejudice-related conflict: In search of a nutshell. Personality and Social Psychology Bulletin, 22, 461473.

O’Brien, L. T., \& Crandall, C. S. (2003). Stereotype threat and arousal: Effects on women's math performance. Personality and Social Psychology Bulletin, 29, 782-789.

Ostrom, T. M., Skowronski, J. J., \& Novak, A. (1994). The cognitive foundation of attitudes: It's a wonderful construct. In P. G. Devine, D. L. Hamilton, \& T. M. Ostrom (Eds.), Social cogni- tion: Impact on social psychology (pp. 195-258). New York: Academic Press.

Pettigrew, T. F. (1997). Generalized intergroup contact effects on prejudice. Personality and Social Psychology Bulletin, 2, 175-185.

Priester, J. R., \& Petty, R. E. (1996). The gradual threshold model of ambivalence: Relating the positive and the negative bases of attitudes to subjective ambivalence. Journal of Personality and Social Psychology, 71, 431-449.

Priester, J. R., \& Petty, R. E. (2001). Extending the bases of subjective attitudinal ambivalence: Interpersonal antecedents of evaluative tension. Journal of Personality and Social Psychology, 80, 19-34.

Scott, W. A. (1969). Structure of natural cognitions. Journal of Personality and Social Psychology, 12, 261-278.

Scott, W. A. (1966). Measures of cognitive structures. Multivariate Behavior Research, 1, 391395.

Smith, E. R. (1993). Social identity and social emotions: Toward new conceptualisations of prejudice. In D. M. Mackie \& D. L. Hamilton (Eds.), Affect, cognition and stereotyping: Interactive processes in group Perception (pp. 297-315). San Diego, CA: Academic Press.

Stangor, C., Sullivan, L. A., \& Ford, T. E. (1991). Affective and cognitive determinants of prejudice. Social Cognition, 9, 359-380.

Stephan, W. G., \& Stephan, C. W. (1993). Cognition and affect in stereotyping: Parallel interactive networks. In D. M. Mackie \& D. L. Hamilton (Eds.), Affect, cognition, and stereotyping: Interactive processes in group perception (pp. 111-136). Orlando: Academic Press.

Thompson, M. M., \& Holmes, J. G. (1996). Ambivalence in close relationships: Conflicted cognitions as a catalyst for change. In R. M. Sorrentino \& E. T. Higgins (Eds.), Handbook of motivation and cognition: Foundations of social behavior (pp. 479-531). Guilford Press: New York.

Thompson, M. M., Zanna, M. P., \& Griffin, D. W. (1995). Let's not be indifferent about (attitudinal) ambivalence. In R. E. Petty \& J. A. Krosnick (Eds.), Attitude strength: Antecedents and consequences (pp. 361-386). Mahwah, NJ: Erlbaum.

Trafimow, D., \& Sheeran, P. (1998). Some tests of the distinction between cognitive and affective beliefs. Journal of Experimental Social Psychology, 34, 378-397.

Turner, J. C., Hogg, M. A., Oakes, P. J., Reicher, S. D., \& Wetherell, M. S. (1987). Rediscovering the social group: A self-categorization theory. Oxford, England: Basil Blackwell.

Watson, D., \& Tellegen, A. (1985). Toward a consensual structure of mood. Psychological Bulletin, 98, 219-235. 
Watson, D., Wiesie, D., Vaidya, J., \& Tellegen, A. (1999). The two general activation systems of affect: Structural findings, evolutionary considerations, and psychobiological evidence. Journal of Personality and Social Psychology, 76, 820-838.

Zanna, M. P., \& Rempel, J. K. (1988). Attitudes: A new look at an old concept. In D. Bar-Tal \& A. W.
Kruglanski (Eds.), The social psychology of knowledge (pp. 315-334). Cambridge, England: Cambridge University Press.

Received December 11, 2009 Revision received March 22, 2010 Accepted May 17, 2010 